\title{
Critical Thinking in the Digital Age: Strategies of Human Resource Management
}

Olga E. Ivanova ${ }^{+}$

\section{Abstract}

The research introduces a strategy of utilising critical thinking (CT) as an instrument of developing professional skills set in the digital age. The research aims to evaluate the potential of CT in human resources management (HRM). It has been established that the strategy of CT offers a way of intellectual improvement within the framework of professional communication. Therefore, a systematic fostering of CT allows for successful integration of affective and cognitive aspects of communication in the context of HRM.

Conversely, this research has identified the potential of the offered strategy in change- and risk management. The CT strategy has proved itself to be an effective way of professional decisionmaking in key cognitive aspects as well as in effective ones (intellectual courage, perseverance, confident reasoning, independent thinking in tandem with overcoming egocentrism and sociocentrism). Based on the results of the empirical research within the modern digital environment, the long-term efficiency of the offered strategy has been substantiated; the researchers have outlined the potential ways of implementing the results of the study, as well as strategy's growth point.

Keywords: Management; Human Resource; Digital Generation; Critical Thinking; Strategies of Critical Thinking; Affective Strategies; Cognitive Strategies; Potential

\footnotetext{
† South Ural State Humanitarian Pedagogical University, Russian Federation, Email: 74oliva@mail.ru (C) 2019 Ivanova. This is an Open Access article distributed under the terms of the Creative Commons Attribution License (http://creativecommons.org/licenses/by/2.0), which permits unrestricted use, distribution, and reproduction in any medium, provided the original work is properly cited.
} 


\section{Introduction}

The modern world is characterised by the constant exponential growth of data (Temnova \& Mednikova, 2017). Internet users generate 2.5 quintillions of bytes of information daily, and apparently. In recent years, there has been intense development of digital technology that now provides us with a gateway to HRM Big Data, the defining trait of which is that "the data can be transferred with ever-increasing speed, regardless of its complexity or diversity" (Franks, 2014: 116). In this set of circumstances, the authors are facing the necessity of interpreting and analysing large masses of detailed information; which requires a particular set of cognitive skills aimed at solving various problems.

Apart from that, the organisational structure itself is gradually transforming from a bureaucratic hierarchy with its downward model of communication to a decentralised adhocracy (Toffler, 2002), represented by temporary work collectives, created to handle unconventional problems. On the one hand, an adhocracy goes lockstep with post-industrial society: permanent change on the global scale, short-term employer-employee connection as well as constant migration of personnel, in other words - "the continuous organisational revolving" (Toffler, 2002: 314). On the other hand, adhocracy is different from the old system in principle and therefore requires a new level of behavioural and intellectual flexibility.

As a result, the authors may observe that in a new fast-evolving world, characterised with high speed of technological progress, the capability to think critically is in high demand. CT can be defined as an ability "to plan one's actions in advance and to think fluently but not without persistence and ability to correct one's mistakes and to seek compromises if need be" (Halpern, 2000: 213).

The relevance of studying a methodology based on CT has also been acknowledged by the World Economic Forum in Davos (WEF - 2016), where it was classified as a basic skill, which is in strong demand by employers around the globe "for many industries" (World Economic Forum, 2016: 23).

The authors' recourse to the subject is motivated by the necessity to analyse the philosophical and methodological attitude of the new generation of workers - the "techno-junkies", "IGen", "Z", "NetGen", "digital natives", "generation of 9/11", "generation of selfie", "centennials". (Horovitz, 2012; Higa, 2016; Broadbent et al., 2017; Stillman, 2018). The generations spawned in a high-tech environment, which will define the perspective of its further development with regard to their abilities and needs.

The article begins with a review of the literature and the justification regarding the potential of CT under conditions of data redundancy in a rapidly changing world. The sections that follow discusses the research methods, a framework for evaluating HRM strategies, the context (samples, conditions and participation procedures), and the possible limitations, as well as data analysis criteria. Empirical results, outlined in detail, form a framework for the SWOT-analysis of HRM strategies and for the algorithmisation of the management decisionmaking process. The analytical assessment and interpretation of issues surrounding the HRM strategies complete the study.

\section{Literature Review}

Upon analysis of the research on the subject of this study, the researchers observe that current interest to CT as a critical element of Soft Skills is actualised by the need of an effective solution to personal and professional problems caused by the redundancy of information.

It can also be said that the expert opinions on what constitutes CT are divided. However, the researchers may bring them to a common denominator by listing the abilities deemed necessary for CT by all specialists: interpretation, analysis, reasonable judgement, drawing logical conclusions, self-regulation (Facione, 1990; Bermingham, 2015). The commonality of views allows avoiding the discussion over the structure 
of $\mathrm{CT}$, and related criteria for assessment thus enables the judgmental analysis.

In the study of CT potential, it is presumed that CTcan be defined as scientific thinking (Volkov, 2016), that is, the ability to self-reflect and selfregulate (Klimanova, 2016); based on simple logic and oriented towards the practical part of the task (Kalashnikova \& Tokareva, 2016). This results in what is generally called "innovative thinking" which stems from rationality, creativity and intellect (Kalashnikova, 2015; Tikhonova, 2018; Al Jarrah, 2019). These characteristics of CT define the utilisation of Paul's strategies within the transdisciplinary concept of HRM and are included in the questionnaire form (Paul \& Binker, 1990).

To explore the potential of HRM in the community of youth, this research appeals to different points of view. Salleh, Mahbob \& Baharudin (2017) point out the relation between modern society development and CT. On the one hand, CT is a defining psychological characteristic of modern youth (generation Z) (Maletin, 2017). On the other hand, their ability to think critically has not yet been developed to its full potential (Temnova \& Mednikova, 2017).

On the other side, the practitioners point to insufficient competence like CTamong the digital generation and call it one of the core problems of HRM. Owing to the lack of a complete skill set of CT, modern-day HR-managers are forced to deal with this problem regularly (Tulgan, 2013; Hiring 2013 College Graduates, 2013; Turner, 2015).

In this context, the aim of this research is dedicated to solving it by offering a new HRM strategy, which aims to unlock the potential of the new generation via bolstering their capacity to $\mathrm{CT}$.

\section{Materials and Methods}

\section{Research Design}

The method of critical analysis served as a basis of evaluating the efficacy of CT; while SWOTanalysis allowed the authors to discover the way that various internal and external factors influence the offered strategy.
The framework of the study is a transdisciplinary concept of CT. The concept defines CT as a disciplined intellectual process that leads to "self-improvement (in thinking) through standards (that assess thinking)" (Paul \& Binker, 1990: 87). Thirty-five principles of CT (Paul \& Binker, 1990), formulated within this concept, were transformed into a questionnaire.

\section{Research Sample and Survey}

In addition to that, a survey via Google Forms was conducted. Access panels served as a method to generate samples. The target attributes of the respondents were age (to fall within the target demographics(generation Z"youth born in the mid-1990s through the late 2010s" (Turner, 2015: 108); their social status as criteria definable by the capacity to self-analyse and use CT professionally. Thereby, the selection was represented by 1-2 year Bachelor students studying in state universities in Russia in 20182019. A total of 351 people participated in the survey ( $N=351$; women - $68 \%$, men - $32 \%$; 17 year-olds - $26.3 \%, 18$ year-olds - $33.3 \%, 19$ yearolds - $40.4 \%)$.

All respondents received an invitation via email mentioning the conditions of the survey (an active Google account, age, anonymity) to fill in the form at their convenience. The time required to complete the questionnaire was no more than 10 minutes. The respondents did not have the option of changing the answers upon completion. At the end of the survey, the students were able to look at the results in form of graphs.

The analytical assessment of CT strategy was based on the principle of self-evaluation, assuming that $\mathrm{CT}$ is characterised not only by being able to analyse others but also by the propensity to self-analysis. Taking to account the low potential validity of self-assessment data, the researchers also considered the results of modern sociological studies (Kuh, 2001; Pike et al., 2012; Porter, 2013).

The respondents were provided with all necessary information; the questions were formulated clearly and explicitly and pertained 
to recent activities only. The survey was anonymous - in order to obtain objective answers. Thus, in the absence of disclosure of personal information, the answers do not threaten with negative consequences. The data received by self-assessment is potentially valid (Porter, 2013).

It has been offered to the respondents to evaluate their own strategies of CT by marking the specific range on the spectrum ("always or nearly always", "most of the time", "rarely or never") founded on the international system of CT evaluation: "strong, acceptable, weak" (Facione \& Facione, 1994: 1): 1; 2; 3 respectively. Based on the input data, the researchers assessed the respondents' strategies of CT in percentage. Standard deviation calculation (Microsoft Excel) has allowed the researchers to determine the volatility.

\section{Results and Discussion}

The strategy of CT constitutes a method of problem-solving together with the findings, generating and exchanging production values. According to Paul's classification (Paul \& Binker, 1990), 35 dimensions of critical thought can be divided into three categories: one affective, comprising 9 aspects (S1-S9), and two cognitive, comprising 26 aspects - micro-skills (elementary skills, S10-S26) and macro-abilities (ability to use two or more micro-skills simultaneously, S27S35). The proposed ratio does not indicate the prevalence of cognitive strategies over effective ones. Both groups of strategies are closely interlinked. Cognitive micro-skills serve as basis for macro-abilities. The function of effective strategies is to broaden the range of cognitive strategies: "One cannot develop one's intellectual independence without actually thinking independently" (Paul \& Binker, 1990:202). As was established by P. A. Facione's study, the individuals with developed affective disposition, "are much more likely to apply their CT skills appropriately in both their personal life and their civic life than are those who have mastered the skills but are not disposed to use them" (Facione, 1990: 32).
Throughout the analytical evaluation of CT methodology, the following strategies were studied in groups and individually. The results of SWOT-analysis are presented in Table 1.

Based on this study, the researchers categorised dispositions with $p>50$ as CT strengths in the range "always or nearly always" (1), comprising of affective strategies, cognitive micro-skills and macro-abilities.

It was discovered that the most successful CT effective strategies are "developing intellectual good faith" (58.8\%) and "exploring thoughts and feelings" (54.2\%) (Elder \& Paul, 2019: 22). The most effective cognitive macro-ability was proved to be "analytical evaluation of actions or policies" (56.4 \%), most effective cognitive micro-skill - "recognising contradictions" (Elder \& Paul, 2019:23) (see Table 2). What is more, a relatively high level of efficacy was demonstrated by "intellectual humility and suspense of judgement" (50.4\%). However, the dimensions such as "developing insight into egocentricity or sociocentricity" (an affective strategy) and "practising Socratic discussion", which require additional clarification of meaning and logic, were marked as weakness by $32.2 \%$ of respondents.

The highest standard deviation was registered in the category of effective strategies, which could indicate inability either to overcome egocentrism or to recognise limits of one's knowledge (see Figure 1). The lowest volatility was registered in elementary skills.

The chief factors defining the weaknesses were pointed out to be CT's high labour-intensity and potential discomfort of implementation, since practising CT requires cumulative application of discipline, humility, courage and perseverance; as cultivation of these values enhances the potential of the strategy,which, in its turn, will facilitate unimpaired, well-founded and contextually justified decision making in the sphere of HRM. If implemented systematically, CT strategies allow one to create a flexible system defined by instrumental sustainability and effective management (Ivanova et al., 2019; Israfilov et al., 2019). 
Table 1: SWOT Analysis of Critical Thinking Strategies

\section{Strengths}

1. Intellectual good faith or integrity (S7)

2. "Exploring thoughts and feelings" (S4)

3. Analytical evaluation of actions or policies (S20)

4. Recognising contradictions (S34)

5. Integration of CT strategies (S1-S35)

\section{Weaknesses}

1. Developing insight into egocentricity or sociocentricity (S2)

2. Practising Socratic discussion (S24)

3. Reading critically (S21)

4. Volatile benchmark of effective strategies

5. Intellectual humility and suspense of judgement (S5)

6. CT's high labour-intensity and potential discomfort of implementation

\section{Opportunities}

1. Pragmatic/constructivist approach to HRM

2. Algorithmisation of HRM

3. Defining and verifying tasks per SMART criteria

4. Systematic cultivation of CT

5. Formalised assessment of management effectivity

\section{Threats}

1. Advocacy of ideology, authoritarianism and dogma

2. Skill-gaps in the absence of systematic cultivation of $\mathrm{CT}$

3. Ignoring potential problems and not taking measures to prevent them 4. Avoiding risks or change

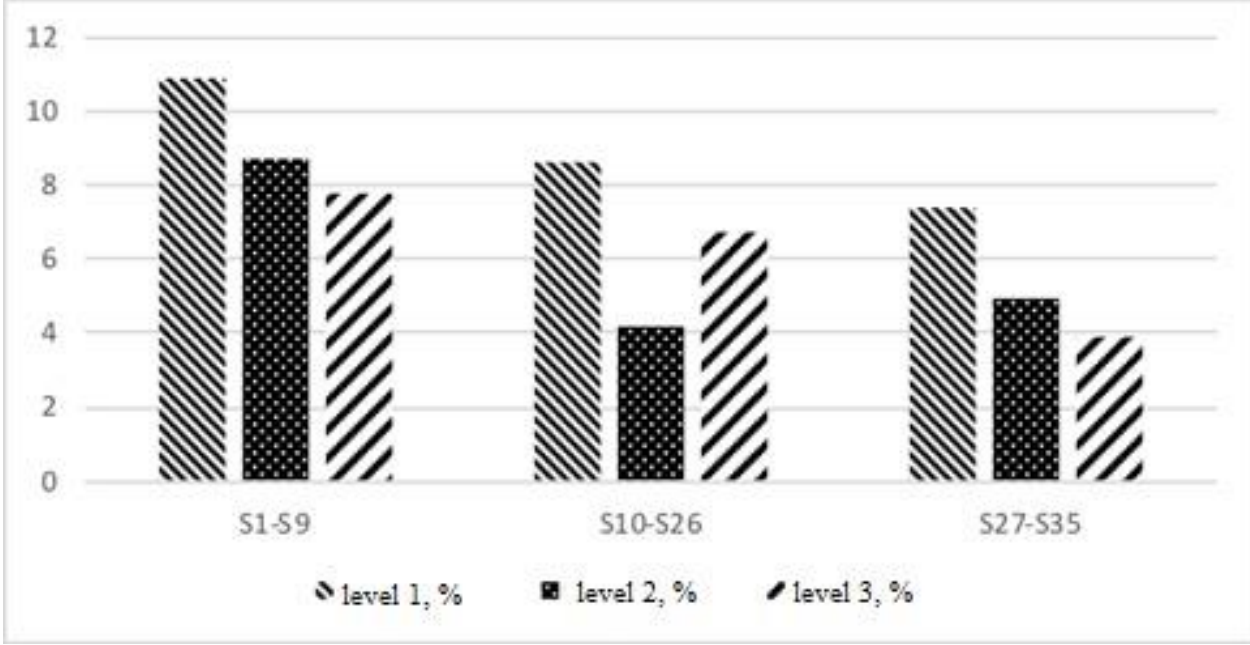

Figure 1: Standard Deviation of Critical Thinking Strategies Source: Developed by the Author

Productive constructivism is applied to CT through the prism of two main principles: criticality and creativity - and thus provides an opportunity to solve problems unconventionally and to evaluate business projects without prejudice.

Algorithmisation of management decisions in HR is recommended in implementing key cognitive skills (techniques), which "increase the probability of obtaining the desired result", provided that their use is "well founded and potentially effective in this specific situation" (Halpern, 2000: 215).
Thus, the correlation between the stages of traditional management decision-making, pertaining to mentioned cognitive skills and subskills is presented in Table 3 (Facione, 1990).

Systematic cultivation of CT must be founded on practical education as well as the individual's own experience of trial and error. One of the most effective formats of being acquainted with CT strategies is through the workshops teaching debate and problem-solving.

Implementing CT strategies in HRM efficiencyassessment allows developing many management skills evaluated by the SMART 
Table 2: Self-Assessment in Critical Thinking (CT) Strategies

\section{CT Strategy}

S1. Thinking independently

S2. Developing insight into egocentricity or sociocentricity

S3. Exercising fair-mindedness

S4. "Exploring thoughts and feelings"

S5. Developing intellectual humility and suspending judgement

S6. Acquiring intellectual courage

S7. Developing good intellectual faith/integrity

S8. Acquiring intellectual perseverance

S9. Forming confidence in reason

\section{Average}

\section{Standard deviation}

S10. Refining generalisations and avoiding

oversimplifications

S11. Comparing analogous situations

S12. Creating or exploring beliefs, arguments, or theories

S13. Clarifying issues, conclusions, or beliefs

S14. Clarifying and analysing the meanings of words or phrases

S15. Developing criteria for evaluation: clarifying

values and standards

S16. Evaluating the credibility of sources of information

S17. Questioning deeply

S18. Analysing or evaluating arguments,

interpretations, beliefs, or theories

S19. Creating or assessing solutions

S20. Analysing actions and policies

S21. Reading in a critical manner

S22. Listening in a critical manner

S23. Making interdisciplinary connections

S24. Practicing Socratic discussion

S25. Reasoning dialogically

S26. Reasoning dialectically

\section{Average}

Standard deviation

S27. Comparing and contrasting ideals with actual practice

S28. Thinking precisely about thinking: using critical vocabulary

S29. Noting significant similarities and differences

\section{Quality of CT (in percentage)}

\section{1}

35.6

25.3

31.9

54.2

50.4

42.8

58.8

48.6

44.3

43.5

10.9

44.9

49.6

40.6

38.5

46.4

29.6

40.9

35

39.1

40.2

56.4

26.6

36.7

30.1

21.1

41

35.4

38.4

8.6

42.7

32.6

42.5
2

55.8

42.5

59.3

35.3

35.9

13.7

44.9

34.9

43.4

47.1

44.3

8.7

47.1

41.5

49.7

8.9

9.7

10.9

7.7

45.9

13.7

13.1

9.7

12.6

48.3

9.4

3.8

22

17.7

19.5

32.2

10.6

14.6

13.1

6.7

9.7

19.5

8.6

\section{6}

2.2

8.8

2.3

8

8.6

7.8

0.5

3.7

2.1

8

9

10.9




\begin{tabular}{|c|c|c|c|}
\hline S30. Examining or evaluating assumptions & 39.4 & 50.6 & 10 \\
\hline $\begin{array}{l}\text { S31.Distinguishing between facts, relevant and } \\
\text { irrelevant }\end{array}$ & 42 & 47.4 & 10.6 \\
\hline $\begin{array}{l}\text { S32. Making plausible inferences, predictions, or } \\
\text { interpretations }\end{array}$ & 33.8 & 53.6 & 12.6 \\
\hline $\begin{array}{l}\text { S33. Giving reasons and evaluating evidence and } \\
\text { alleged facts }\end{array}$ & 24.6 & 57.4 & 18 \\
\hline S34. Comprehending contradictions & 50.3 & 39.4 & 10.3 \\
\hline S35. Examining the implications and consequences & 38.8 & 50.9 & 10.3 \\
\hline Average & 38.5 & 49.3 & 12.2 \\
\hline Standard Deviation & 7.4 & 4.9 & 3.9 \\
\hline
\end{tabular}

\begin{tabular}{|c|c|c|c|}
\hline & Stage of Decision-Making & Skill & Sub-skill \\
\hline 1 & $\begin{array}{l}\text { Analysing the problem, } \\
\text { defining boundaries }\end{array}$ & Interpretation & $\begin{array}{l}\text { Categorisation } \\
\text { Decoding Significance } \\
\text { Clarifying Meaning } \\
\end{array}$ \\
\hline 2 & $\begin{array}{l}\text { Defining the goal and the } \\
\text { criterion of success }\end{array}$ & Analysis & $\begin{array}{l}\text { Examining Ideas } \\
\text { Identifying Arguments } \\
\text { Analysing Arguments }\end{array}$ \\
\hline 3 & $\begin{array}{l}\text { Gathering information, } \\
\text { analysing the alternatives }\end{array}$ & Evaluation & $\begin{array}{l}\text { Assessing Claims } \\
\text { Assessing Arguments }\end{array}$ \\
\hline 4 & $\begin{array}{l}\text { Choosing the optimal } \\
\text { solution }\end{array}$ & Inference & $\begin{array}{l}\text { Querying Evidence } \\
\text { Conjecturing Alternatives } \\
\text { Drawing Conclusions }\end{array}$ \\
\hline 5 & Execution & Explanation & $\begin{array}{l}\text { Stating Results } \\
\text { Justifying Procedures } \\
\text { Presenting Arguments }\end{array}$ \\
\hline 6 & $\begin{array}{l}\text { Feedback, further } \\
\text { clarification; control }\end{array}$ & Self-regulation & $\begin{array}{l}\text { Self-examination } \\
\text { Self-correction }\end{array}$ \\
\hline
\end{tabular}

criteria (Specific, Measurable, Achievable, helps to overcome discord and enhances Relevant, Time-bound) by means of MBO decision-making" (Dalio, 2018: 401).

(management by objective) methodology. This allows HRM to eliminate double standards Potentially this approach provides an and establish a flexible communication system; opportunity to weed out flawed concepts, added to which, the mentioned CT strategies - if beliefs and conclusions.

Thus, CT opposes the way of corporal function characterised with authoritarianism and dogma, where the absence of CT considerably undermines productivity. The achievement of "new corporate culture" can only be based upon the principles of transparency, honesty, meaningful work algorithms and learning from one's mistakes; "so that all members of the team find themselves on the same page project-wise, without being afraid of repercussions. cultivated regularly - can be employed in other corporate structures with similar success.

Furthermore, practising effective CT strategies jointly, taking intellectual courage (S6) and intellectual perseverance (S8) for example, allows one to handle peer pressure when it comes to defending the logically proven efficacy of an unpopular measure, based off one's skill to confidently step into professional debate (59) 
Along the same line, to neutralise the atmosphere of intellectual reluctance, it is necessary to distinguish facts and beliefs (S13); to filter relevant facts from the general pool of information (S31), and to have a vigorous intent to find the underlying cause of any problem (S17).

\section{Conclusion}

The focus of strategic $\mathrm{CT}$ is increasingly relevant in the fast-evolving post-industrial world. The literature review suggests a judgmental selection of CT skills. These skills, depending on what they are and on their order, form the core for the algorithmisation of the management decision-making process. Paul's strategy of effective CT is relevant to the core characteristics of $\mathrm{CT}$ like being reasonable, reflective, rational and contribute to innovative thinking. Apart from this, the review opens a problem in HRM, which is defined as an insufficient level of CT competency in generation $\mathrm{Z}$.

As a long-term direction, CT strategies imply selfimprovement through the utilisation of intellectual standards in problem-solving. Thus, mentioned CT strategies offer a way to improve professional thinking while raising the bar of intellectual competence.

The potential of the offered strategies is attained through systematic cultivation of CT skills in both affective and cognitive aspects, that is, intellectual courage and persistence, confident reasoning, overcoming ego- and sociocentrism in order to enhance employees' competence in risk- and change management.

All mentioned principles, implemented in a communication environment unrestricted with bureaucracy and unnecessary hierarchical intervention, lead to a positive development in employees' micro-skills and macro-abilities. In its turn, this creates an effective mechanism of setting and achieving relevant managerial goals. The theoretical basis of the research was substantiated by empirical research, which resulted in the following conclusion: the general way of thinking among "generation $Z$ " is congruent with offered CT strategies. Accordingly, cultivating skills related to CT promotes professional growth and offers numerous ways of bolstering the efficacy of goalsetting and decision-making strategies.

\section{References}

Al Jarrah, H. Y. (2019). Six Thinking Hats: An Analysis of the Skill Level of Jordanian Vocational Education Teachers and the Extent of Skill Application. Space and Culture, India, 7(1), 170-185. doi: 10.20896/saci.v7i1.470

Bermingham, M. (2015). Clearing up "Critical Thinking": Its Four Formidable Features. Creative Education, 6(04), 421. doi: 10.4236/ce.2015.64042

Broadbent, E., Gougoulis, J., Lui, N., Pota, V., \& Simons, J. (2017). Generation Z: global citizenship survey. What the World's Young People Think and Feel? (pp. 120). London: Varkey Foundation.

Dalio, R. (2018). Principles: Life and Work (pp. 608). Moscow: Mann, Ivanov \& Ferber.

Elder, L., \& Paul, R. (2019). The Thinker's Guide to Analytic Thinking: How to Take Thinking Aapart and What to Look for When You do. London: Rowman \& Littlefield.

Facione, P. (1990). Critical Thinking: A Statement of Expert Consensus for Purposes of Educational Assessment and Instruction (The Delphi Report). Retrieved on 12 January 2018 from, https://philarchive.org/archive/FACCTA

Facione, P. A., \& Facione, N. C. (1994). Holistic Critical Thinking Scoring Rubric: A Tool for Developing and Evaluating Critical Thinking. Retrieved on July, 19, 2007 from, http://www.deanza.edu/slo/icctaskforce/ sample_rubric_gittens.pdf

Franks, B. (2014). Taming the Big Data. Finding Opportunities in Huge Data Streams with Advanced Analytics (pp. 352). Moscow: Mann, Ivanov \& Ferber.

Halpern, D. (2000). Critical Thinking Psychology (pp. 512). St.Petersburg: Piter. 
Higa, D. (2016). Meet Generation Z: The Digital Natives. Retrieved on 12 January 2018 from, http://kaohana.windward.hawaii.edu/201 6/02/meet-generation-z-the-digitalnatives/

Hiring 2013 College Graduates (2013). Retrieved on 12 January 2018 from, https://www.shrm.org/hr-today/trendsand-forecasting/research-andsurveys/Pages/hiring2013collegegraduate s.aspx

Horovitz, B. (2012). After Gen X, Millennials, What Should Next Generation be? USA TODAY. Retrieved on 12 January 2018 from,http://usatoday30.usatoday.com/m oney/advertising/story/2012-0503/naming-the-nextgeneration/54737518/1

Israfilov, N.T., Shnyreva, E.A., Panfilova, E.E., Bozhko, L.M. \& Konstantinov, V.A. (2019). Market Information and Entrepreneurship Education: A Case of Transition Economies. Journal of Entrepreneurship Education, 22 (3), 1528-2651-22-3-383.

Ivanova, O. E., Ryabinina, E. V., \& Tyunin, A. I. (2019). Pragmatic Constructivism as a Soft-Methodology of the HRM Concept. International Transaction Journal of Engineering, Management, \& Applied Sciences \& Technologies, 10 (2), 245-253.

Kalashnikova, N. (2015). The Role of Critical Thinking in Innovative Social Environment Formation. The Newsletter of the Volgograd State University. Series 7. Philosophy, 4 (30), 127-133. doi: 10.15688/jvolsu7.2015.4.16

Kalashnikova, N., \& Tokareva, S. (2016). Critical Thinking and Logical Culture of Personality and the Models of the Possible World. The Newsletter of the Volgograd state university. Series 7. Philosophy, 4 (34), 183-187. doi: 10.15688/jvolsu7.2015.4.16

Klimanova, A. (2016). Ideas about Critical Thinking in the Minds of Today's Youth. The Newsletter of Herzen State
Pedagogical University of Russia, 180, 5158.

Kuh, G. D. (2001). The National Survey of Student Engagement: Conceptual framework and overview of psychometric properties. Bloomington, IN: Indiana University Center for Postsecondary Research, 126.

Maletin, S. (2017). Features of Consumer Behavior of Generation Z. Russian Entrepreneurship, 18 (21), 3347-3360.

Paul, R. W., \& Binker, A. J. A. (1990). Critical Thinking: What Every Person Needs to Survive in a Rapidly Changing World. Center for Critical Thinking and Moral Critique, Sonoma State University, Rohnert Park, CA 94928.

Pike, G. R., Smart, J. C., \& Ethington, C. A. (2012). The Mediating Effects of Student Engagement on the Relationships Between Academic Disciplines and Learning Outcomes: An Extension of Holland's Theory. Research in Higher Education, 53(5), 550-575. doi: 10.1007/s11162-011-9239-y

Porter, S. R. (2013). Self-Reported Learning Gains: A Theory and Test of College Student Survey Response. Research in Higher Education, 54(2), 201-226. doi: $10.1007 / \mathrm{s} 11162-012-9277-0$

Salleh, M. S. M., Mahbob, N. N., \& Baharudin, N. S. (2017). Overview of "Generation Z" Behavioural Characteristic and its Effect Towards Hostel Facility. International Journal of Real Estate Studies, 11 (2), 5967.

Stillman, D. (2018). Gen Z at Work (pp. 272). Moscow: Mann, Ivanov \& Ferber.

Temnova, L., \& Mednikova, M. (2017). The Impact of Virtual Space on Communication of Representatives of Generations $Z$ and Y. Theory and Practice of Social development, 11, 19-23.

Tikhonova, V. (2018). Critical Thinking Formation as the Basis of Developing 
Students' Leadership Qualities. A Manuscript, 10 (96), 92-95.

Toffler, A. (2002). Future Shock (pp. 557). Moscow: AST Publishing house.

Tulgan, B. (2013). Meet Generation Z: The Second Generation Within the Giant" Millennial" Cohort. Rainmaker Thinking, (125).

Turner, A. (2015). Generation Z: Technology and Social Interest. The Journal of Individual Psychology, 71(2), 103-113. doi: 10.1353/jip.2015.0021

Volkov, Y. (2016). Learning Scientific (Critical) Thinking Skills and Visual Objectivization of Knowledge: Content, Practices, Tools. The Bulletin of Lobachevsky University in Nizhniy Novgorod. Social sciences series, 2 (42), 199-203.

World Economic Forum. (2016, January). The Future of Jobs: Employment, Skills and Workforce Strategy for the Fourth Industrial Revolution. In Global Challenge Insight Report, World Economic Forum, Geneva.

\section{Acknowledgements}

The reported study was funded by RFBR according to the research project No. 19-01000322 